\title{
Cerebral Arteriovenous Malformation
}

National Cancer Institute

\section{Source}

National Cancer Institute. Cerebral Arteriovenous Malformation. NCI Thesaurus. Code C2936.

An abnormal connection between arteries and veins characterized by the absence of intervening capillaries in the brain. Signs and symptoms include headaches, bruit upon head examination, seizures, and bleeding. When bleeding occurs, the signs and symptoms are similar to those in stroke. 